\title{
Technology, Innovations and Industrial Development
}

\section{Nikolay Sterev ${ }^{*}$ \\ Héctor Gerardo Toledo Rosillo**}

\begin{abstract}
Technology development, inventions and innovations are at the heart of the contemporary economic development and industrial growth. The continuous internationalisation and the fostering of social and business networking are two main forces that change not just society but overall development. Furthermore, they lead to a shift in global aims and objectives.

Despite the economies, technologies and political systems, inventions and innovations have never stopped for a while over the last 4 centuries. They are always an instrument that strengthen the state and make life better. To manage overall growth, governments need to shape inventions and innovations in the right direction. Hence, the contemporary industrial policy is based on clear evidence of a strong link between past innovations and growth and expectations about their future dynamic change.
\end{abstract}

The main research question is how innovations, economic development and growth, and National Economic Goals are, or should be, inter-connected. Thus, the paper aims to make a brief review of contemporary research in the field of innovations, industrial growth based on innovations, and innovations strategies.

The structure of the paper is as follows: 1. Introduction: the problem and basic concepts; 2. Literature overview: a brief review on the innovations and their role for the economic development; 3. Methodological approach: discussion on evaluating economic growth and its dependence on innovations; 4. Policy recommendations: some main features of the Growth and Innovation Strategy 2020; 5. Conclusions: some remarks on the future development.

Keywords: Technology, innovations, industrial development

JEL: F63 L52, O14, O31, O41

\section{Introduction}

nventions and innovations are part of

industrial growth as the newly emerged technologies and products have driven the technological processes and sales to a new and higher level.

As the very first signs of industrial growth were based on the accidental inventions in the Middle Ages, the beginning of Industrial development started with the change of routine labor operations with machine operations the First Industrial Revolution. Then, industrial growth witnessed an exponential replacement of the labor with machines - The Second and Third Industrial Revolutions. But as industrial growth was based on the pure organization

\footnotetext{
* Professor, University for National and World Economy, Dept. of Industrial Business.

** Professor, Autonomous University of Querétaro (UAQ), Mexico.
} 
of technological processes, while innovations were based on the use of new materials and new operations' instructions and manuals since 2000s, innovations today are quite different - they are based on the Artificial intelligence (Al) and industrial growth is based on the self-learning machines - the Fourth and Fifth Industrial Revolutions (Figure 1).

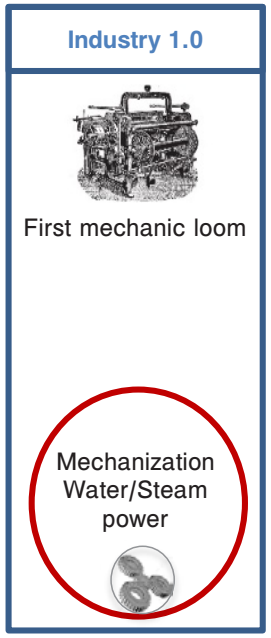

1784

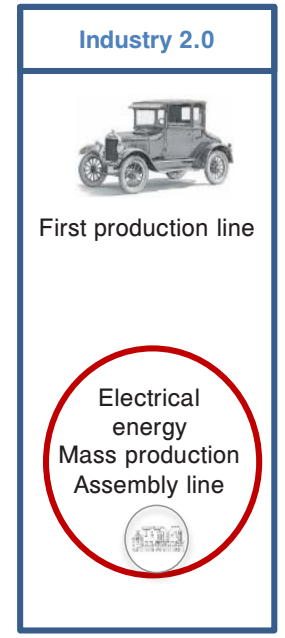

1870

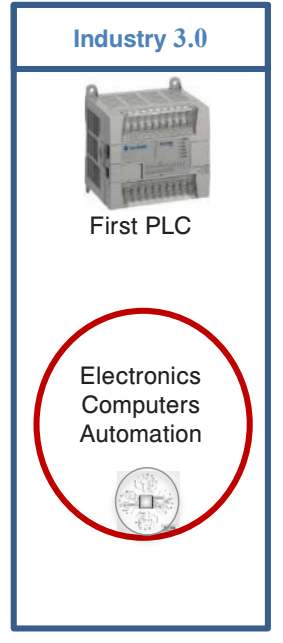

1969

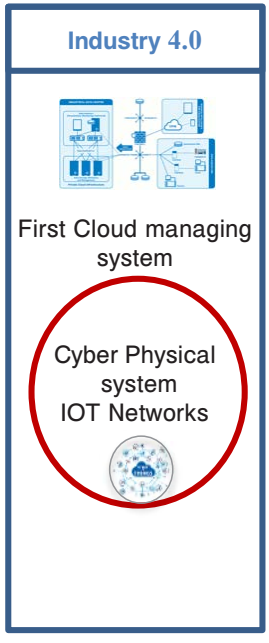

2009

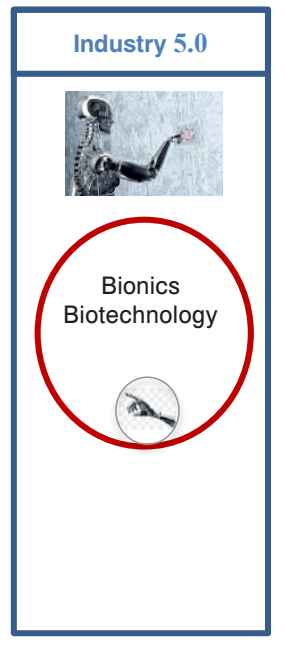

? 2035 ?

Figure 1. Industry Revolution Stages

Source: Modification of T\&A (Taskforce \& Advisor Sàrl), https://www.ta-ad.biz/en/tindutrie-4-0

So, it is very important to analyse how technologies and innovations are transferred to growth.

\section{Technology and innovation}

Few are the days where the words "technology" and "innovation" are not present in our lives, in our conversations, in the news or in a simple message from our cell phone requesting an update of some software or application that we have installed. We live in an era where technological innovation is experienced on a daily basis, where we receive notifications of new changes and advances at all time, where the pace and scope of the changes that organizations/ companies produce has never been seen before in the history of mankind. The speed at which the changes occur, especially talking about innovations, is amazing indeed.

Globalization, our demands as users and consumers and the intensification of competition are speeding up technological advances at a higher level of competition. Although innovation has been widely studied, it has two aspects that have been commonly mentioned in its definition - novelty and application (Revilla, 2001) ${ }^{1}$. This refers to the fact that we should have a very clear idea about the difference between an invention or a creative idea and an innovation.

- The invention is that creative idea that arises basically from a process of creativity and research, but not necessarily used or embodied in a product, process or service.

- On the other hand, innovation is the commercial application of that creative idea. In other words, it covers the process of converting ideas into new or improved products, processes or services that the market values. According to the book written and coordinated by Elena Revilla (2001) ${ }^{1}$, together with the COTEC 


\section{Articles}

Foundation (Spain), some examples of definitions of innovation are mentioned: Schumpeter (1939) studies the process as a whole; Tushman (1977) analyses innovation as an information process; Rogers (1983) focuses on dissemination as part of the innovation process; Cooper (1984) approaches it from the perspective of the success of the strategies of product innovation; Von Hippel (1988) emphasizes the importance of users as sources of innovation; Van de Ven (1989) investigates the direction of innovation; Porter (1990) relates innovation with competitiveness; Muñoz-Seca (1992) links innovation with learning and training; and so on.

Innovation is a synonym of change. When a company or person is innovative this means that it is evolving, changing, doing new things, creating new manufacturing processes, offering new products to consumers, etc. Innovating is a process of daring to do something different and new. It means taking something, destroying it and rebuilding it completely upside down. Nowadays, this is what companies value most, since they are obliged to be innovative if they want to survive in this changing world. Basically because if they do not innovate, competitors will inevitably catch up with them.

Yet what happens when a product does not get a position in the market and / or a benefit, even if the product or process works in a creative or technical sense? What really happens is that the innovation becomes a failure. And this is something that happens fairly frequently.

As we know within the five steps of the diffusions of innovations, we find the initial part of knowledge (which is to discover the existence of this innovation), but the third part, which is the decision, is extremely important and it is where one decides if innovation is accepted or rejected by the individual, group or organization.

And speaking about the current great trend of innovation and specifically talking about technology, we could define three fundamental points of this changing trend:

- first, technical progress (which is basically finding new and frequent technologies to produce and create products),

- secondly, the internationalization of the economy because of growing competition, not only with neighbouring countries, but with the whole world; and

- the third factor is the customizing of the markets, that is, the tendency to manufacture more personalized products, tailored to specific markets (Escorsa and Valls, 2001) ${ }^{2}$.

The relationship between innovation and technology is really close. There are few words that when asking about the topic of innovation, do not give you an answer related to technology. And yes, technological development is a very clear example of the innovations that are made in this area. We know that many universities, companies and government invest a lot of time and budget to what we know as R\&D (Research and Development), which can be divided into three classes: fundamental basic research, applied research and technological development. Basic research includes those studies and works that are carried out to have new scientific knowledge. We usually find them published in specialized books or journals, and it is the slowest and most complicated research process. After having that knowledge, an applied research is carried out, which is basically putting a practical objective to that knowledge. Normally what you get are what is known as patents. But it is up to the stage of technological development that knowledge is used to produce materials, 


\section{Articles}

devices, procedures, systems, new services or substantial improvements. In brief, the first goal of technological development is to launch a novelty or a concrete improvement to the market (Escorsa and Valls, 2001) ${ }^{2}$.

The concept of technology is often linked to the technology of machines, devices or apparatus, but it is in fact much more than that. The Royal Spanish Academy (RAE) ${ }^{3}$ gives the following definition: "set of theories and techniques that allow the practical use of scientific knowledge". ${ }^{3}$ In other words, it is the practical application of knowledge generated by science. Presumably since the late twentieth century we are in the fourth industrial revolution and during this period we have had many examples of significant advances for the world in technology issues: the internet, fibre optic connections, breaking communication barriers between people of other countries, as well as a new economic revolution where physical elements become virtual, manufacturing processes are intelligent and robotized, where man does not even interfere in the production process, emergence of new sources of work, areas of study such as nanotechnology, biotechnology, robotics, renewable energies, computer science, robotics, 3D designs, quantum processes, strengthening of the aerospace industry, web applications, smartphone development, strengthening of the pharmaceutical industry and different areas of medicine, development of the arms industry, virtual connections and social networks, unmanned vehicles and supplied with renewable fuel, recycling of raw materials, advances in genetics, digital genome, among many more examples that we have in our daily life (Maldonado, 2016) ${ }^{4}$. This means that talking about technology is talking about many aspects of our daily lives. And there is no way to talk about technology without also talking about innovation, considering that they have such a close relationship and that one cannot function without the other. But what can we really see as development or technological advancement in 2018 or over the next five years?

The innovation in technology for 51 years has been carried out in the Consumer Electronics Show (CES), where for years inventions and innovations have been presented to sound and video equipment (such as DVDs in its time) or the transition from colour televisions to LED TVs. In 2018 several ideas and prototypes were presented. Some examples that could be seen are the following: Bell Helicopter (a USA company started in Texas and which currently has an office in Mexico City since 2015) presented a prototype of its air taxi for four people, which it hopes to put into operation in partnership with Uber in the middle of 2020. In the presentation they only presented a prototype under a virtual reality simulator, but who would think that in two years we could see a flying taxi? Mercedes-Benz presented Smart Vision $E Q$, an electric car and also autonomous. With a simple call, the vehicle will pick up the person from where he is. Talking about automatic vehicles, the e-Palette, which is created by Toyota and Amazon, where they will offer product delivery services to homes and transport of people on specific routes (El Tiempo, 2018). ${ }^{5}$

Perhaps all these examples seem still very far from our reality and current life, but this is not the case. An example of a product that is a real thing that a person can use, is the implemented on 21 January 2018, the Amazon company, which has its headquarters in Seattle. It opened the first supermarket in which it is not necessary to stand in line to pay for the products. It is not necessary to go through a cashier, nor is a purchase receipt delivered. It is real, it is not prototype and it is called Amazon Go. The only thing that is 


\section{Articles}

essential to be able to use the service is a smartphone.

But how does it really work? When entering the store or supermarket, with the smartphone you must pass the code on the entry bar and with that the different sensors and cameras detect not only the smartphone but the entire body of the person. The shelves where the products are located are full of sensors that at the moment when a product is extracted or returned, it is detected in the online purchase automatically of the application. This means that the sensors detect customers and control the products they take. In the end the purchase is automatically charged from the account/credit card that is registered and the customers simply leave the store. I do not know if Amazon will open more supermarkets, but what is known is that this is already proven and is real.

Another example of a technological advance that is in our hands is the Alexa technology that consists of software created by Amazon and introduced a couple of years ago in the market. The technology answers questions and performs tasks through voice commands. For example, Alexa can program, turn on and off the wake-up alarm in the mornings, only by talking to her (it must be in English), you can play the music you have in connection with the cell phone in the application Spotify, increase or decrease volume; you can turn on the television, change channels or even put a movie on Netflix; can give a summary of the news highlights of the world or national day, among many other functions that can be programmed: for example reading a recipe while preparing it at the same time. It's real, all through commands and voice instructions (in English). It is a technology that has a cost of approximately USD 150 and although there are certain functions that are not yet $100 \%$ defined, it seems that it is a technology that was not thought to be used so quickly.
From experience it can be argued that technological advances are becoming faster and far more useful. They solve or facilitate functions of daily life that we did not even realize existed. The things that we have always considered science fiction, are becoming normal things in our lives. We have also heard a lot about the Internet in recent years. The concept itself refers to any device, in addition to the traditional computer and mobile, that can be connected to the Internet anywhere and anytime. We could give some examples: sports sneakers that measure the distance and time of travel during an exercise session, synchronized via Bluetooth so that you can keep track of daily routines. Another example is the locks or smart doors, which through an app via Bluetooth or wireless internet, can give access to people or open or close a door. The option of ovens or kitchen appliances that are handled remotely to prepare the food that you leave prepared before only to finish cooking, all through an app on your smartphone. We can give examples of nanotechnology in clothing, when they show us a jacket or sweatshirt that although it is submerged in water, if we remove it, it remains dry to the touch. We had never thought some years ago that our cell phones would be unlocked with a face and faction detector, and that even if you have a twin sister it will be so precise to differentiate it. All this is reality that we can buy, acquire and use already in our lives. And if it is not yet a reality, it will not be long before the lines between "real" reality and augmented reality begin to fade, as with lenses and headphones that are presented by brands such as Sony or Samsung.

"The scientific community has a wonderful tradition of creating instruments that help us visualize the world in totally new ways. For example, the microscope has helped us to see objects that are too small for the human eye, and the thermometer has helped us 


\section{Articles}

understand the temperature of the Earth and the human body," said Dario Gil, Vice President of Science and Solutions at IBM Research. ${ }^{6}$ "With advances in Artificial Intelligence and nanotechnology, we aim to invent a new generation of scientific instruments that will make the complex invisible systems of our world today visible in the next five years" (IBM, 2018). Each year the IBM company publishes the five predictions of emerging technologies in the company's laboratories throughout the world.

For more than seven decades, IBM Research has defined the future of information technologies, with more than 3,000 researchers in 12 laboratories located on six continents. The scientists of IBM Research have produced six Nobel Prizes, 10 National Medals of Technology of the United States, five National Medals of Science of the United States and six Turing Awards. ${ }^{6}$

We will explain three of the five innovations that were proposed for this 2018. The first is artificial intelligence for the benefit of our mental health. As IBM explains in its publication, today, one out of every five adults in the United States experiences a mental health condition, whether neurological, (Huntington, Alzheimer, Parkinson, etc.) or mental (depression or psychosis). Each year, approximately half of the people with severe psychiatric disorders do not receive treatment. Globally, the cost of treating mental disorders is greater than the cost of diabetes, respiratory problems and cancer, all combined (IBM, 2018). What they are developing is that through computation analysis of the spoken or written words of a patient, we can find an indicator of some type of mental illness or also be able to track their treatment and it would let us know immediately if we have any reason to consult a doctor.

The second prediction is that in the next five years, the new on-chip medical labs will serve as health nanotechnology detectives tracking invisible clues in our body fluids.

As we know, the prevention and early detection of a disease raises the levels of being able to be cured or treated. But many times the diseases are not detected until long after the first symptoms occur. What has been worked on is to be able to build chips that monitor our organism to indescribable levels.

Another prediction is the smart sensors that will detect environmental pollution. For example, methane is the second largest pollutant and causes global warming. In the United States, gas and oil emissions are the largest industrial sources of methane gas in the atmosphere. The United States Environmental Protection Agency (EPA) estimates that in 2014, more than nine million metric tons of methane infiltrated natural gas systems. If we measure it as equivalent to $\mathrm{CO}_{2}$ - equates to more than 100 years - it corresponds to more greenhouse gases than those emitted by the United States in iron and steel, cement and aluminium manufacturing facilities; all combined. (IBM, 2018). ${ }^{5}$

The above is a brief explanation of how much technology is expected to advance and what can come to solve problems or offer help in our lives. Thinking about innovations in technology is thinking about what is happening all the time. It would seem impossible to think that there were no more advances, when the news shows us that daily there is research focused on creating innovations and technological developments. Technology can be applied in many sectors such as food, health, tourism, sports, clothing etc.

\section{Measuring Industrial Growth and Innovations}

Theories of economic growth appear in the middle of 20th century due to the expansion of markets in countries with "capitalist" form of management of the economy. Thus, the 


\section{Articles}

growth theories follow supplementing the general economic (political economy) theory basic mechanisms that underlie modern (for 1950s and 1960s) free market conditions. Yet innovations are not set as variable that push up industrial growth.

At the very beginning of understanding industrial revolution's prediction, the first single growth model as proposed by Solow and Swan (Authors, 2018; Walker, 2013). In the model two predictions are offered:

- Variable - the economic result (quantity or in money) that any single business aims to produce.

- Inputs - the different opportunity costs that effect on the variable. It is very important that we have economic decision model that express how different inputs are related each other

$$
Y=f(L, K, \alpha)
$$

(Formula 1)

where $Y$ - variable (production, income), $L$ - labor input, $K$ - capital input (land in the 17-18th century) and $\alpha$ - efficiency of labor force (the efficiency of capital is 1-a)

Development of the Solow growth model is found to exchange labor for capital (land and machinery) (Solow, 1956; Makiw, Romer and Weil, 1992):

$$
\mathrm{Y}(\mathrm{t})=\mathrm{A}(\mathrm{t}) \cdot \mathrm{L}(\mathrm{t})^{\alpha} \cdot \mathrm{K}(\mathrm{t})^{1-\alpha}
$$

The change of parameters is based on time and we could use it for long-term periods.
Thus, any single business had to use or to find out the most efficient way (basically to optimize costs at given production/sell for a short term period) of production at any time.

Initially the theory of economic growth is used as a providing arguments or criticism of the existing status quo of economic neoClassical, neo-Keynesians, monetarists and other economic flows (Stoyanov 1992). In this phase of the adoption of the theory of growth, most characteristic is that the position of the factors identified as a source of growth have been changed. So many internal company factors attributable to the policies and strategies of business organizations are defined as factors directly on the change of the growth of the entire economic system. According to the aforesaid, critics argue that the first economist Schumpeter paid particular attention to the internal variables of growth. Its growth theory is called "theory of evolution" because of the analogy with the development of other systems - biological, physical, etc.

The most significant contribution for understanding innovations and their role to industrial growth is based on Schumpeter's theory presented as a model of the turnover of the economic system (Figure 2), the growth of the economic system upsets the balance in the turnover and "drives" the system to take a new position.

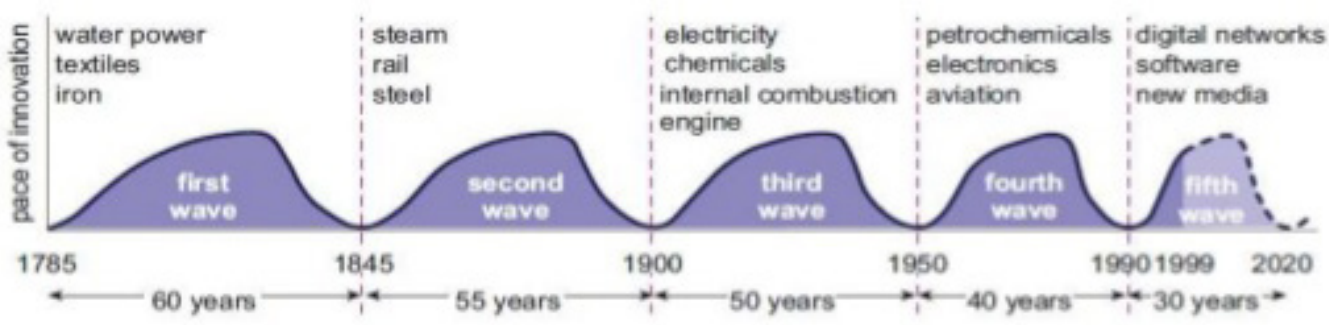

Figure 2. Model of the turnover of the economic system 


\section{Articles}

The most important feature is the institutionalization of the developer - a leader, innovator, creator which destroyed the traditional, creating new added value in society and promoting the development of the economic system.

After Schumpeter's theory of growth is supplemented by artists like Herbert Simon, Nelson and Winter, Demean and others. They utilized for a Schumpeterian entrepreneur economic system growth, and developed terms and conditions of this growth. For example, Simon binds the theory of growth with the theory of organizational behaviour and thus economic growth is the result of an economic rationality in companies. Thus, growth is not a result of a search for optimal solutions and the adoption of satisfactory and acceptable ones. Nelson and Winter in turn extend the rational behaviour of Simon and put forward a new figure that is important for growth - namely, the creator of the new. In the view, the development of the organization of production and technology is a result of demand and the creation of new knowledge.

So, the augmented model of growth model added new inputs as resources (R) and innovative costs (M) (Sterev, Kopeva and Blagoev, 2017)

$$
Y(t)=A(t) \cdot L(t)^{\alpha} \cdot K(t)^{1-\alpha} \cdot R(t)^{\beta} \cdot e^{M(t)}
$$

(Formula 3.)

Nowadays the theory of growth is developed by Eliasson, Carlson, Marleba and other European authors. Their theories, however, are directed more towards the study of the growth of various levels as studying microeconomic and macroeconomic growth and the relationship between them. Thus Eliasson concluded that the growth of an individual business is related to the sustainability of the development of the entire economic system. Moreover, the greater the variation in companies, the more sustainable is the growth of the economy as a whole. The explanation is called "Brownian motion" of business within the economic system.

Using the achieved development of growth theory by Eliasson the growth model pays less attention on demand diversity in the business at the micro-level. The researcher offers a model for the resolution of technical problems that does not depend on market demand and external factors to the existing economic system but depends on variety of technical solutions.

The social aspects of innovations are put into social growth models. They study the change of the economic system contingent on the change of entrepreneurship level. Thus, Gong (2004) evaluates the business growth by introducing 3 different groups of enterprises (entrants, exits and cumber) and estimates their added value as the next ${ }^{1}$ :

$$
\Delta Y=\frac{\sum_{i \epsilon C} \theta_{i t-1}\left(\Delta y_{i t}\right)+\sum_{i \epsilon C} \Delta \theta_{i t} \Delta y_{i t}}{\sum_{i \in C} \theta_{i t} y_{i t}-\sum_{i \epsilon C} \theta_{i t-1} y_{i t}}
$$

(Formula 4.)

According to the above equations, the aggregate function of the growth social network model could be as follows:

$$
\ln \Delta Y=\frac{\sum_{i \epsilon C} \theta_{i t-1}\left(y_{i t-k}-\bar{Y}\right)+\sum_{i \epsilon E} \theta_{i t}\left(y_{i t}-\bar{Y}\right)}{\sum_{i \epsilon C} \theta_{i t}\left(y_{i t}-\bar{Y}\right)-\sum_{i \epsilon X} \theta_{i t-k}\left(y_{i t-k}-\bar{Y}\right)}
$$

(Formula 5.)

Analysis of the impact of the innovations, their level and the role of innovators, are needed to set effective measures for enforcing growth by supporting inventions and innovations.

\section{National Innovation Program}

The milestones of the EU Strategy 2020 introduce the needed connection between business governance and growth as a set of mechanisms for encouraging innovations

\footnotetext{
1 Sekkat (2010) gave another expression of the intragroup production value.
} 
following the three most important economic pillars:

- transitioning to a knowledgebased economy by better business management and developing R\&D networking;

- encouraging private research investment and R\&D partnerships;

- modernizing the European social model by investing in people.

Thus economic development is based on the main growth-driven factors: innovations, business actors' networking and development, and the inter-linkages between them. However, the national adjustment for small countries of the Innovation and Growth Strategy 2020 has to be based on the following economic threats:

- Highly dependence on foreign markets and foreign investment as a very small economy;

- The competitive advantage of a national economy has been formed on the basis of the low prices of the basic factors labor, natural resources and energy;

- The share of highly innovative business based on technology innovation, productivity improvement, research and technological development is very low.

Therefore, to strengthen the long-term competitiveness of the economy by introducing industrial policy, it is highly recommended to set as core pillars of Innovation and Growth Strategy 2020 as well as to be supported by the national operational framework ${ }^{2}$ :

- Smart growth: developing the economy system based on knowledge transfer and product, and technology innovations;

- Sustainable growth: promoting a greener economy and the more efficient use of limited natural resources such as water, soil and minerals;

- Inclusive growth: fostering a highemployment economy based on higher value added by the labor force through social and regional cohesion.

The expected result of the implementation of the Innovation and Growth Strategy 2020 and financing the measures through National State Fund mechanisms can be summarized as follows:

- establishment of an innovation-friendly business environment;

- modernizing the business infrastructure for sustainable and competitive growth and labor improvement;

- establishment of the basic for innovationdriven and resource-efficient restorative economy;

- introduction of successful instruments for effective cooperation between business, academia and universities;

- accelerate the access to finance, especially for SMEs and start-ups.

To elaborate the given results two additional supporting strategies are needed:

1. National Strategy for Promotion of Small and Medium-Sized. It presents the vision of the Government on the needed state policy support in the field of the establishment SMEs as well as the development of SMEs' networking and the involvement of SMEs in international consortia of production chains. In addition, under the measures of the strategy, there will be support for the establishment of new SMEs allocated to the relevant sectors of the economy, particularly in the area of industry and knowledge intensive services.

2. Innovative Strategy for Intelligent Specialization until 2020. It presents the

2 OPIC 2014-2020, 2014BG16RFOP002 - March 2015, http://www.opcompetitiveness.bg/images/filerepository/3733_OPIC _2014_2020_adopted_by_EC_16.03.2015_EN.pdf. 


\section{Articles}

environmental conditions that will help to ensure the achievement the of Innovation and Growth Strategy 2020's objectives. The main areas of Innovative Strategy for Intelligent Specialization establish and manage the coordination of innovations; national innovation system and scientific infrastructure; specific financial support instruments for product and technology innovations; support for digital growth and e-Government.

In conclusion, enforcing industrial growth through innovations should be focused on increasing the productivity, efficiency and innovativeness of the enterprises. Appropriate Innovation and Growth Strategy and its financial programme provides measures for stable growth through establishing the support, development and cooperation between export-oriented and/or knowledgebased high innovation SMEs with high added value production.

\section{Conclusion}

The technology that has been discovered over the years can be accessible to a large part of the population. The appearance of so many developments and technological advances have even contributed to a significant lowering of the costs of acquiring these technologies, compared to a few years ago. The procedures to implement these advances are simpler to do and the sales prices of certain products are now reasonable enough. Gradually there will be attempts to possibly make technology available to everyone. In a follow-up paper it would be important to evaluate why countries such as Mexico and Bulgaria, among others, have not had an exponential growth in technological development and innovations, which can basically be explained by the lack of investment in science and technology. Even though these countries have been for centuries independent in their economy, the latter is subordinated to the interests of the most developed (capitalist) countries (De la Peña, s.f) ${ }^{6}$. If they (resp. Mexico, Bulgaria and others) wish to advance in their economic development and growth, they should set the goal to intensify R\&D in order to remain at the forefront and satisfy the unlimited desires of society.

\section{REFERENCES:}

Authors (2018), Models of Economic Growth (With Diagram) | Macroeconomics

Carlsson, B., Eliasson, G. (2001). "Industrial dynamics and endogenous growth", paper prepared for the Nelson and Winter Conference of the Danish Research Unit for Industrial Dynamics (DRUID), June, available at: www.druid.dk/conferences/nw/

Dosi G. and F.Malerba (2003). "Special Issue on Industrial Dynamics",Industrial and Corporate Change, 11, 619-633.

Elena Revilla y Fundación COTEC (2001). Innovación Tecnológica. Ideas Básica. Pág. 12

Eliasson, G., (1998). "Competence Blocs and Industrial Policy in the Knowledge Based Economy". OECD Science, Technology, Industrial (STI) Revue;

Gong, Y. Q., (2004). Entry, exit and the dynamics of productivity growth in Chinese manufacturing industry, ESRC Centre for Business Research, University of Cambridge, Working Paper No. 284

IBM. Enero, 2018. Recuperado el 21 de junio del 2018 de: http://www.research.ibm. com/ En español: https://www-03.ibm.com/ press/mx/es/pressrelease/51344.wss

Javier Alejandro Maldonado (2016). La ciencia y tecnología: su importancia en la vida cotidiana. Recuperado el 21 de junio del 2018 en: http://www.milenio.com

Kopeva D. N.Sterev, D.Blagoev (2010), Factor Limitations on Industrial Dynamics in 


\section{Articles}

Bulgaria in Conditions of European Integration, Economic Alternatives Journal, 2EN/2010, pp. 40-59

Luis de la Peña A (s.f) Ciencia y Tecnología en México, país dependiente. Recuperado el 24 de junio del 2018 de: http://www. revistaciencias.unam.mx/es/153-revistas/ revista-ciencias-10/1309-cienciay-tecnolog\%C3\%ADa-en-m\%C3\%A9xico,pa\%C3\%ADs-dependiente.html

Makiw, N.G., D.Romer, D.Weil (1992). A contribution to empirics of economic growth, Quarterly Journal of Economics, Vol. 107, Issue 2/May 1992, p. 407-437, https://eml.berkeley.edu/ dromer/papers/ MRW_QJE1992.pdf

Pere Escorsa y Jaume Valls. (2001) Tecnología e innovación en la empresa. Pág. 22

RAE (Real Academia Española). www.rae. es/

S/Autor (Enero, 2001). El CES de Las Vegas: un vistazo al futuro. Recuperado el 21 de junio del 2018 en: http://www. eleconomista.es/tecnologia/ noticias/7637602/06/16/Diez-avancestecnologicos- que-veremos-en-los-proximosdiez-anos.html

Sekkat K. (edd.), 2010, Market Dynamics and Productivity in Developing Countries, International Development Research
Centre, Springer Science+ Business Media, LLC 2010

Solow, R. (1956). A contribution to Theory of Economic growth, Quarterly Journal of Economics, Vol. 70, Issue 1/Feb. 1956, p. 65-94, http://www.jstor.org/stable/1884513

Sterev, Kopeva \& Blagoev, Industrial Dynamics at national level as a factor of sustainable industrial growth in EU, 3rd European Conference on Corporate R\&D (CONCORD-2011):The dynamics of Europe's industrial structure and the growth of innovative firms, 6th October 2011, Seville, Spain

Sterev, N., D. Kopeva, D. Blagoev (2017). Does Business Cycle Have an Impact on Entrants and Exits?, International Journal of Business \& Economic Sciences Applied Research, Mar2017, Vol. 10 Issue 1, p49-54. Stoyanov D., Industrial growth, UP Stopanstvo, 1993 (in the Bulgarian language)

Walker, J.R., (2013). Macroeconomic Models of Economic Growth, University of Wisconsin, http://www.ssc.wisc. edu / walker/wp/wp-content / uploads/2013/09/E448lec7slides2013.pdf

Winter S., Y.Kaniovski, G.Dosi, 1998, Modeling Industrial Dynamics with Innovative Entrants, International Institute for Applied Systems Analysis, IR-98-033 /May 1998. 